\title{
Management strategy evaluation: Transdisciplinary and transparent natural resource management
}

\author{
Eileen Hofmann ${ }^{\mathrm{a}}{ }$, Lisa Maddison ${ }^{\mathrm{b}}$, and Ingrid van Putten ${ }^{\mathrm{cd}}$ \\ a Old Dominion University, Norfolk, VA, 23508, USA \\ ${ }^{b}$ Institute of Marine Research, Bergen, Norway \\ c Commonwealth Scientific and Industrial Research Organisation, Hobart, Tasmania, Australia \\ d Centre for Marine Socio-ecology, University of Tasmania, Hobart, Tasmania, Australia \\ * Corresponding author. Email: hofmann@ccpo.odu.edu
}

\section{ABSTRACT}

Management Strategy Evaluation (MSE) is a modelling tool used to evaluate sufficiently realistic simulations of potential policy choices in complex systems. As a contribution to the Integrated Marine Biosphere Research (IMBeR) project IMBIZO $\mathrm{V}$, which occurred in October 2017, a workshop was convened with the goal of developing a coherent understanding of bestpractice approaches for MSEs. MSEs are becoming standard approaches to characterizing risk across fisheries management organizations globally. MSEs are important tools that aid in delineating objectives, costs, and constraints that define risk and provide a possible mechanism to meet assessment challenges. The MSE workshop considered case studies drawn from different fisheries (including small- and large-scale fisheries), with associated cultural, societal, and management characteristics, to better define best-practice principles of MSE development, implementation, and communication. The needs and benefits of MSE model development for evaluation of management scenarios for small-scale fisheries were identified. Early career scientists and students were introduced to details of MSE development and implementation, and to colleagues who are part of professional networks that have access to the necessary tools for decisionmaking processes regarding marine resources. Networking and capacity building in MSE expertise in the Asia-Pacific region represent long-term impacts from the workshop.

\section{KEYWORDS}

Fisheries management, IMBeR, IMBIZO, Management strategy evaluation, Small-scale fisheries

\section{DOI}

https://doi.org/10.30852/sb.2019.895

\section{DATES}

Received: 12 March 2019

Published (online): 5 December 2019

Published (PDF): 12 December 2019

\section{HIGHLIGHTS}

» Improved understanding of development and implementation of MSEs for small-scale fisheries.

» Networking and capacity building in MSE expertise in the Asia-Pacific region.

» Early career researchers exposed to MSE issues and associated professional networks.

» Learning opportunity provided by access to a Toy MSE model.

\section{INTRODUCTION}

Marine and human systems are complex, which makes describing their interactions and potential outcomes difficult. Climate change and environmental variability impacts add to the complexity of developing management strategies for marine resource use. Management of fisheries presents challenges because changes in environmental conditions initiate a cascade of responses that appear as social and economic effects. These social and economic responses in turn affect management strategies and policies, which impact the resource.

The Ecosystems Approach to Fisheries (EAF) adopted by the FAO Committee on Fisheries defines Management Strategy Evaluation (MSE) as a modelling-based approach aimed at testing the robustness of possible management arrangements (plans) by examining sets of decision rules, such as those used to adjust total allowable catch or effort controls, to determine which perform best to achieve the management objectives for a fishery (EAF, 
2011). Therefore, the MSE approach allows evaluation of sufficiently realistic simulations of potential policy choices in complex systems and associated robustness to uncertainties (Miller et al., 2010; Bastardie, Vintehr, Nielsen, Ulrich, \& Paulsen, 2012; Martell, Leaman, \& Stewart, 2013; Goethel et al., 2019; Fulton, Punt, Dichmont, Harvey, \& Gorton, 2019). Communication with stakeholders and policy makers to obtain information about the range of desired policy outcomes and acceptable potential policy choices provides constraints for scenarios tested with a MSE (Fulton, Smith, Smith, \& Johnson, 2014; Goethel et al., 2018; Armitage et al., 2019). Challenges to the MSE approach include poorly specified management objectives, a lack of quantitative datasets for developing operating models for many species (Punt, Smith, \& Cui, 2001; International Council for the Exploration of the Sea [ICES], 2019), and robust methods to evaluate risks (Rochet \& Rice, 2009; Goethel et al., 2019).

However, even with these challenges, MSEs have been applied to fisheries (e.g. Punt et al., 2001; Punt, Butterworth, de Moor, De Oliveira, \& Haddon, 2016) and conservation (e.g. Bunnefeld, Hoshino, \& MilnerGulland, 2011, Dichmont et al., 2013) to compare alternative management strategies (Tommasi et al., 2017), while accounting for uncertainty in environmental, biological, and management inputs (Cooke, 1999; Butterworth \& Punt, 1999; Sainsbury, Punt, \& Smith, 2000; Punt et al., 2016). Maintaining the environment is part of the management objectives for some species (e.g., Agnew, Beddington, \& Hill, 2002; Hurtado-Ferro, Hiramatsu, \& Shirakihara, 2010; Pershing et al., 2015; Miller, Hare, \& Alade, 2016), but existing MSEs show mixed results about the effectiveness of alternative, potentially climate-robust, management strategies (A'Mar, Punt, \& Dorn, 2009; Punt, 2011; Szuwalski \& Punt, 2013; Punt et al., 2016; Goethel et al., 2019).

Integrated Marine Biosphere Research (IMBeR), a global environmental change project, has a priority focus on achieving a transdisciplinary understanding of the interactions of ocean-human systems (Hofmann et al., 2015; Hofmann et al., 2016), with emphasis on marine fisheries and their management (e.g. Bundy et al., 2016). To advance progress on MSE applications to marine fisheries, IMBeR convened a workshop as part of its biennial IMBIZO (Zulu word for "a gathering") to assess the current state of MSE implementation for a range of marine fisheries. This workshop focussed on assessing information from natural and social sciences that is essential for MSE development (e.g. the role of institutions), methods and modelling tools for MSE development, methods used to define societal management goals and needs (boundary conditions for the MSE), approaches for MSE evaluation of management options, and development of effective communication strategies to convey MSE predictions (and best-practice principles) to decision-makers.

\section{METHODOLOGY}

IMBeR IMBIZOs are designed to address current research topics, facilitate transdisciplinary research, and provide assessments of current understanding and future research needs. The IMBIZOs consist of concurrent workshops, each of which considers an important research topic. In addition, plenary presentations provide overviews for each workshop, and cross-cutting activities and poster sessions allow integration across workshops. IMBIZO V, held in October 2017 at the Woods Hole Oceanographic Institution, was developed around the theme of "Marine biosphere research for a sustainable ocean: Linking ecosystems, future states and resource management". The workshop on "Management Strategy Evaluation: Achieving Transparency in Natural Resource Management by Quantitatively Bridging Social and Natural Science Uncertainties", was designed to develop a coherent understanding of best-practice approaches to MSEs and serve as a learning opportunity for the attendees.

The workshop considered case studies of different fisheries, cultural, and societal characteristics (including small- and large-scale fisheries in the Asia-Pacific

\begin{tabular}{|l|l|l|l|}
\hline Title & Type & Presenter & Affiliation \\
\hline $\begin{array}{l}\text { Management Strategy Evaluation: Current state and } \\
\text { challenges }\end{array}$ & Plenary keynote & André Punt & $\begin{array}{l}\text { University of Washington, Seattle, WA } \\
\text { USA }\end{array}$ \\
\hline $\begin{array}{l}\text { Looking for robust harvest control rules: Learning } \\
\text { from MSE applications to specific fisheries }\end{array}$ & Invited workshop & Ana Parma & $\begin{array}{l}\text { Centro Nacional Patagónico, Puerto } \\
\text { Madryn, Argentina }\end{array}$ \\
\hline $\begin{array}{l}\text { What good are MSEs when the oceans, and people } \\
\text { that use and manage stuff in them, are so stinking } \\
\text { uncertain? }\end{array}$ & Invited workshop & Jason Link & $\begin{array}{l}\text { NOAA Fisheries Directorate, Woods } \\
\text { Hole, MA, USA }\end{array}$ \\
\hline Toy MSE model presentation & Invited workshop & Gavin Fay & $\begin{array}{l}\text { University of Massachusetts } \\
\text { Dartmouth, MA, USA }\end{array}$ \\
\hline
\end{tabular}

TABLE 1. Summary of title, type, presenter and affiliation for MSE plenary and invited workshop presentations. 


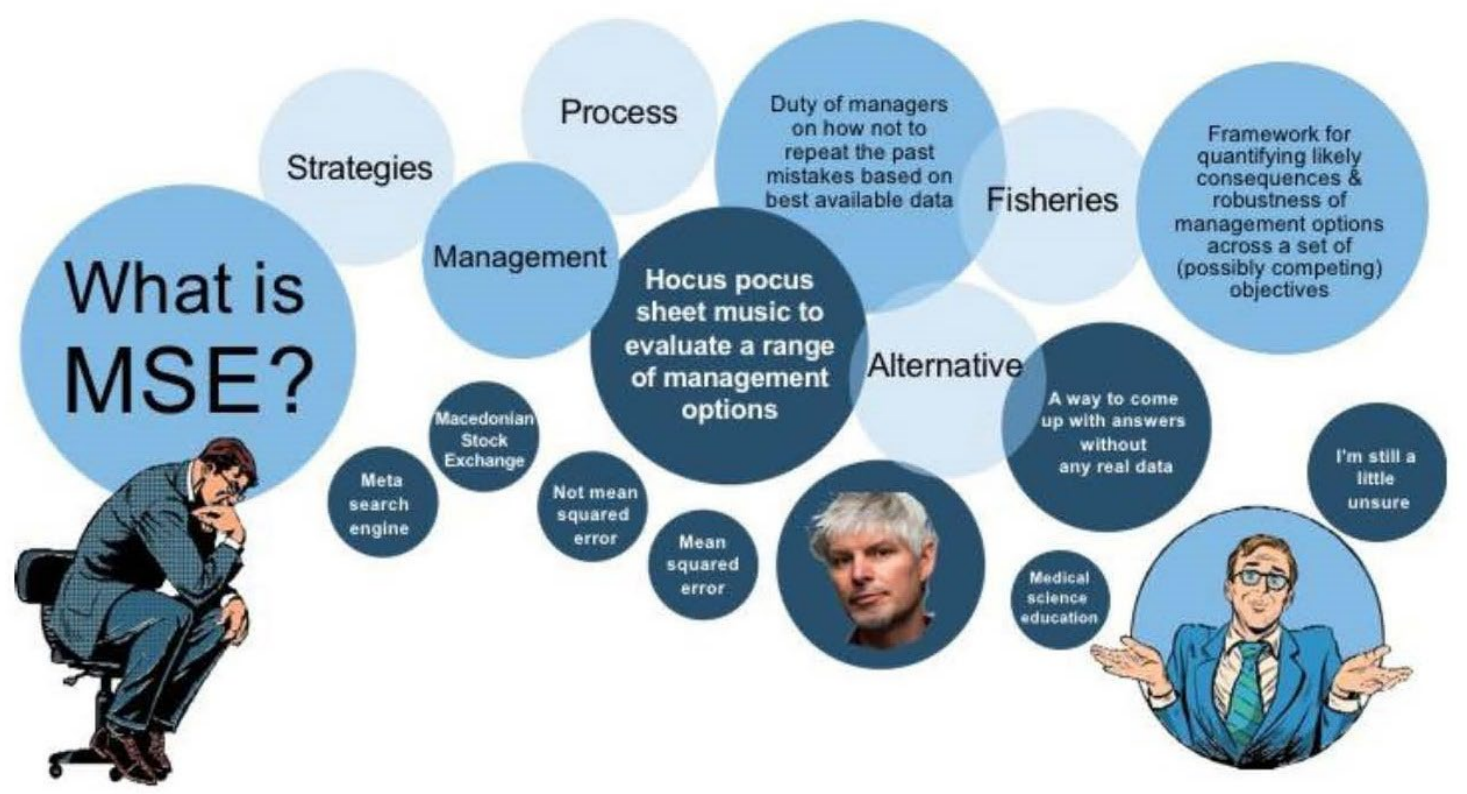

FIGURE 1. Infographic illustrating different perceptions of MSE development and implementation presented by André Punt (inset photograph). The three branches show the difficulty in MSE development and implementation for fisheries and the range of perceptions of MSEs, which include a science-based framework for fishery management (upper), confusion and uncertainty about MSEs (middle branch), and lack of understanding about MSEs and their application (lower branch). The infographic was created by Indi Hodgson-Johnson, University of Tasmania.

\begin{tabular}{|l|c|c|c|}
\hline Country & Student & $\begin{array}{l}\text { Early Career } \\
\text { Scientist }\end{array}$ & Researcher \\
\hline Australia & 1 & & 1 \\
\hline Argentina & & & 1 \\
\hline Bangladesh & & 1 & \\
\hline Brazil & 2 & & 2 \\
\hline Canada & & & 1 \\
\hline China & & & 1 \\
\hline Costa Rica & & 1 & \\
\hline Fiji & 1 & & 2 \\
\hline India & & & 1 \\
\hline Indonesia & 1 & & \\
\hline Japan & & 2 & \\
\hline New Caledonia & & & \\
\hline New Zealand & & & \\
\hline Norway & & & \\
\hline Philippines & & & \\
\hline Romania & & & \\
\hline Solomon Islands & 1 & & \\
\hline Spain & & & \\
\hline Turkey & & & \\
\hline United Kingdom & & & \\
\hline USA & & & \\
\hline Total & & & \\
\hline
\end{tabular}

region) to better define best-practice principles of MSE development, implementation, and communication. The workshop was structured around a keynote plenary presentation and invited workshop presentations (Table 1), as well as oral and poster presentations by workshop participants, and discussions. The workshop attendees represented 21 countries and almost 50\% were students and early career scientists (Table 2).

\section{RESULTS AND DISCUSSION}

\subsection{MSE overview and application}

The keynote plenary presentation (Table 1 ) provided an overview of management issues for fisheries and examples of MSEs that have been applied to fisheries management. Key challenges for MSEs include achieving balanced and meaningful levels of stakeholder involvement, defining appropriate objectives, and effective communication of results.

The keynote presentation set the direction for discussions during the workshop. It focussed on uncertainties inherent in MSEs, which are typically developed to evaluate management strategies for data-poor systems (Figure 1). The three branches suggested in Figure 1 show the difficulty in MSE development and implementation for fisheries, and the range of perceptions of MSEs by managers. The upper branch is the expected progression for a scientific-based approach that leads to a framework that can be used to understand and quantify management 


\section{SMALL SCALE FISHERIES \& MSE}

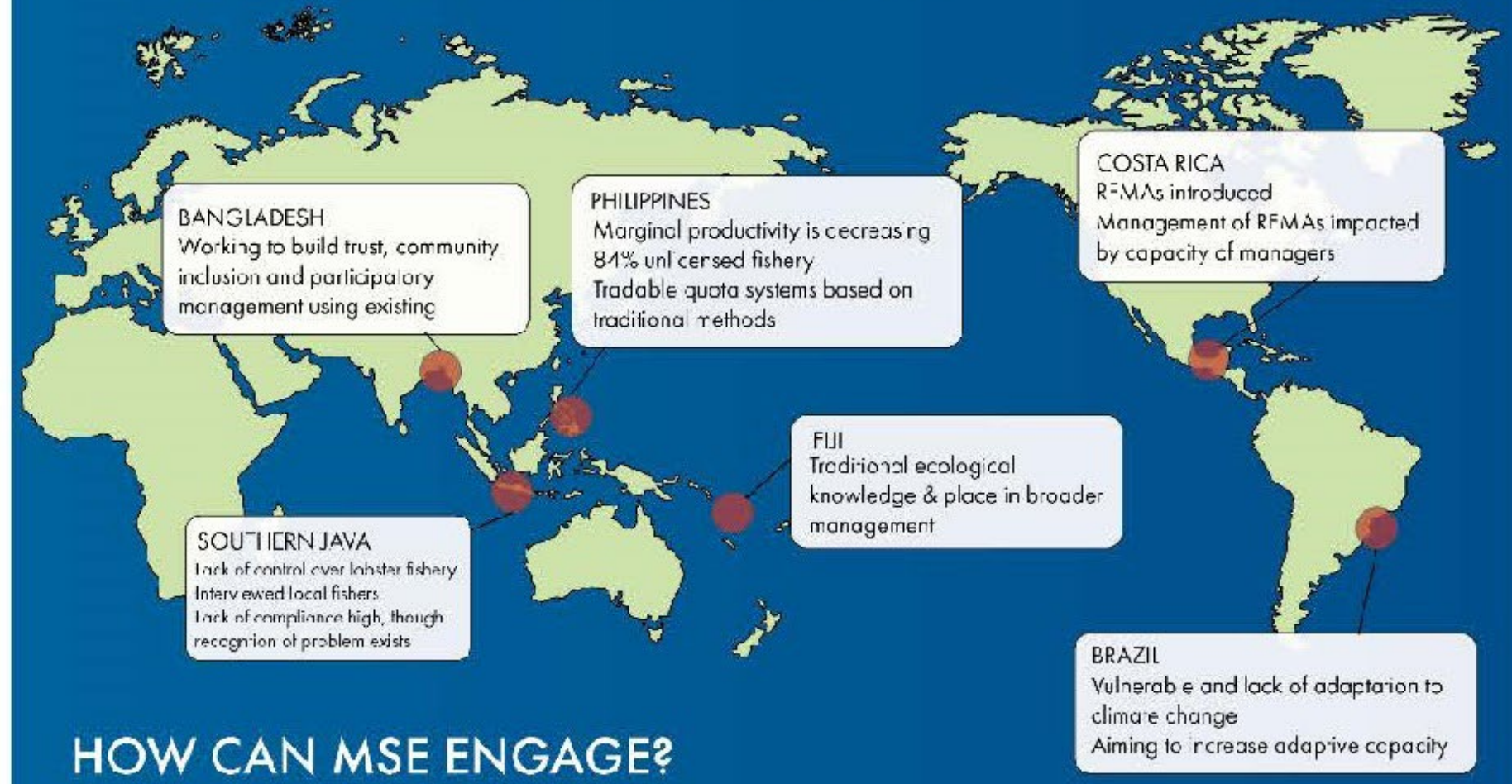

TO ASSIST IN MANAGING..

- SelF-Crganisation

- COMPLIANCE

- APATHY
- LACK O= KNOWLEDGE

- \& UNDERSTANDING

- EXTERNAL FORCES
TO BEAR IN MIND...

- MPORTANCE OF LOCAL ECOLOGICAL KNOWLEDGE

- DIFFERENT DIMEN SIONS (SPAT AL \& TEMPORAL)

FIGURE 2. Infographic summarizing needs of small-scale fisheries and benefits of MSE model development for evaluation of management scenarios. The distribution of the small-scale fisheries discussed at the MSE workshop and their important characteristics are shown. Also shown are the approaches, issues and limitations of MSE engagement identified in discussions. The infographic was created by Indi Hodgson-Johnson, University of Tasmania.

options for fisheries. The middle branch depicts the perception that managers often have of MSE development and outcomes, which is characterized by confusion and uncertainty as to what an MSE is and how it is implemented to assess management options for fisheries. The lower branch suggests that the strengths of MSEs for evaluating management options are not understood or appreciated.

An important point highlighted for MSEs used in the management of fisheries is that learning from previous mistakes is critical (Figure 1, upper branch). This knowledge is needed so that "history does not repeat itself" in the evaluation of management options. The explicit need for detailed datasets is clear, as is that the level of skill required to develop MSEs using time series data is integral to the upper branch (Figure 1) to result in a useful MSE framework. These requirements for expertise and skills to process the data are not equally distributed across countries. For example, low income countries frequently have less access to the necessary specialized skill and detailed datasets are often not available.

The invited talks for the MSE workshop (Table 1) expanded and reinforced the ideas presented in Figure 1. The first presentation focussed on using an MSE to evaluate harvest control rules with specific application to the design and implementation of approaches to rebuild the stock of southern blue fine tuna (Table 1). This presentation clearly articulated social and natural science data needs and provided guidance on defining the societal management goals that underpin MSE implementation. Similarly, the second invited presentation dealt with issues of uncertainty and application of MSEs. The importance of community consultation and involvement was clearly illustrated. Without community 
involvement in developing the MSE and understanding the intent and contents, implementation can be compromised. The third presentation illustrated the natural and social science information needed for an MSE, the MSE as a tool, and again the need for communication of results was emphasized. A "Toy MSE application" developed for the tuna fishery (Table 1) was demonstrated and workshop participants were given access to this model (https://puntapps.shinyapps.io/tunamse). The contributed talks for the MSE workshop dealt with specific aspects and applications of MSEs. In addition, workshop participants considered the application of MSEs to Small-scale Fisheries (SSF), which included examples of several case studies.

\subsection{Advancing MSEs}

The workshop presentations considered aspects of SSFs and the application of MSEs to develop management strategies for these socio-ecological systems.

General themes that emerged from these discussions focussed on barriers to MSE development and implementation. As an important aspect of MSEs, the availability of robust data and time series and reasonably accurate estimates of catches, regular monitoring and data collection is central. In addition, a level of community compliance with the rules is required to be able to predict MSE outcomes with any level of accuracy. The engagement of communities in MSE use requires communities to self-organize and agree to develop compliance procedures for implementation of management strategies (Figure 2).

Barriers to MSE engagement stem partly from a lack of knowledge and understanding, general apathy towards management policies and external factors, such as socio-economic and climate controls. The range of spatial and temporal scales that need to be considered in MSEs was recognized, as well as the importance that data be collected at appropriate scales. Also, inclusion of local ecological knowledge (LEK) was recognized as being critical to successful MSE implementation (Figure 2). The incorporation of LEK was not considered to be straightforward, as no standard procedures were available to incorporate this type of knowledge nor were there generally accepted approaches to verify the "scientific usefulness and accuracy" of local knowledge.

The requirements of the SSFs discussed at the workshop and the benefits of implementing an MSE for management vary with the individual fishery, each of which has unique complexities and differences (Figure 3). The MSE has clear benefits in assisting with decision making and in providing a framework for formalization and integration of information about a system. The MSE also provides a structure for looking at effects that extend

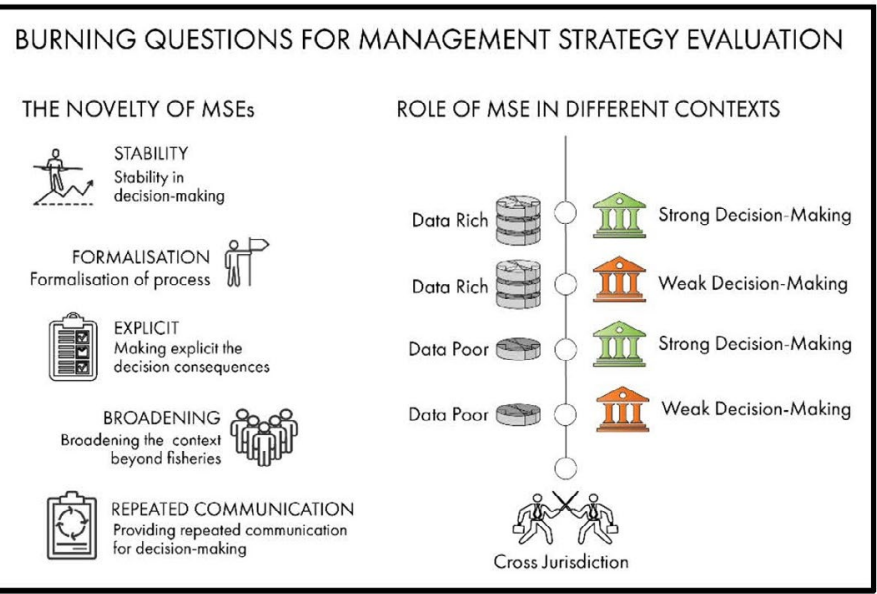

FIGURE 3. Infographic illustrating the capabilities and advantages of an MSE (left panel) and the trade-offs between data availability and the ability of an MSE to support decision-making (right panel). The infographic was created by Indi Hodgson-Johnson, University of Tasmania).

beyond just fisheries and for communicating science and policy. Trade-offs in MSE development and use come from data availability, the need for robust decisions, and the tensions that often arise between communities that develop MSEs and those that implement MSEs (Figure 3).

Best practice procedures for MSEs are outlined in Punt et al. (2016) and include the selection of objectives and performance metrics, selection of uncertainties, identification of candidate management strategies, simulation of the application of the management strategy, presentation of results and selection of a management strategy. The challenges around SSFs with respect to MSE best practices are partly the result of the management situation, including lack of knowledge and data, different culturally specific behavioural responses to rules and regulations, and the ability to include local knowledge in these types of approaches.

To achieve best practice, assessment of the applicability of MSEs to SSFs requires identifying common traits between the two that are amendable to MSE analysis and developing an MSE process that can be applied to data poor and culturally unique situations. Addressing these issues will provide guidance on when an MSE is needed (or not) and identify the core components of the MSE process, including the operation model for SSFs.

\section{CONCLUSION}

In general, MSEs are important tools that aim to help delineate objectives, costs, and constraints that define risk and provide a possible mechanism to meet assessment challenges. MSEs are becoming accepted for identifying different management approaches and characterizing risk across fisheries management locally, regionally, and globally. The workshop convened at 
IMBIZO V is a first step in a longer-term effort to expand the use of MSEs in fisheries management. Research priorities that can be identified on the basis of the workshop results include: i) development of culturally sensitive, effective, and comprehensive community consultation to ensure MSE implementation; ii) defining appropriate objectives and building further knowledge around MSE development and implementation in data poor situations; iii) development of approaches that effectively communicate MSE results and build interactions at the science-policy interface; and iv) development of approaches to continue building capacity of interdisciplinary scientists to ensure a socio-ecological systems approach to MSE.

Participation by students and early career scientists supported by the Asia-Pacific Network for Global Change Research (APN) in the MSE workshop provided exposure to issues surrounding development and implementation of MSEs and the associated professional networks. Access to professional networks, facilitated by the workshop, provided the necessary tools for these individuals to fully participate in decision-making processes regarding marine resources and assessing the usefulness of MSEs in their national context. These workshop participants have a start at understanding the tools that will allow them to fully participate in decision-making process regarding marine resources. Networking and capacity building in MSE expertise in the Asia-Pacific region represent long-term impacts from the workshop. A lesson learned from the workshop is that the development of opportunities for early career scientists especially in countries where SSFs play an important role is critical for MSE development and implementation. Opportunities for identifying relevant data collection and targeted interpretation in SSFs is also key for future undertaking of MSEs. The priorities for future research specific to SSFs and more broadly applicable MSE-related topics provide a tangible approach for capacity building because these will involve early career scientists and dissemination of the workshop results to the larger scientific community.

\section{ACKNOWLEDGEMENTS}

We gratefully acknowledge the sponsorship provided by the Asia-Pacific Network for Global Change Research's CAPaBLE Programme that supported the MSE Workshop. We thank our partners in the Ocean Carbon and Biogeochemistry project office at Woods Hole Oceanographic Institution for the considerable and gracious assistance that they provided to make IMBIZO V successful. Inputs and advice from the MSE Workshop co-convenors, Francisco Werner (NOAA) and Gavin Fay (University of Massachusetts Dartmouth) were invaluable and contributed to the success of the workshop. We thank the MSE Workshop participants for engaging presentations and discussions.

\section{REFERENCES}

Agnew, D. J., Beddington, J. R., Hill, S. L. (2002). The potential use of environmental information to manage squid stocks. Canadian Journal of Fisheries and Aquatic Sciences, 59(12), 1851-1857.

A'Mar, Z. T., Punt, A. E., \& Dorn, M. W. (2009). The impact of regime shifts on the performance of management strategies for the Gulf of Alaska walleye pollock (Theragra chalcogramma) fishery. Canadian Journal of Fisheries and Aquatic Sciences, 66(12), 2222-2242.

Armitage, D. R., Okamoto, D. K., Silver, J. J., Francis, T. B., Levin, P. S., Punt, A. E., ... \& Kitka, H. (2019). Integrating governance and quantitative evaluation of resource management strategies to improve social and ecological outcomes. BioScience. 69(7), 523-532.

Bastardie, F., Vinther, M., Nielsen, J. R., Ulrich, C., \& Paulsen, M. S. (2010). Stock-based vs. fleet-based evaluation of the multi-annual management plan for the cod stocks in the Baltic Sea. Fisheries Research, 101(3), 188-202.

Bundy, A., Chuenpagdee, R., Cooley, S. R., Defeo, O., Glaeser, B., Guillotreau, P., ... \& Perry, R. I. (2016). A decision support tool for response to global change in marine systems: the IMBER-ADApT Framework. Fish and Fisheries, 17(4), 1183-1193.

Bunnefeld, N., Hoshino E., \& Milner-Gulland E. J. (2011). Management strategy evaluation: a powerful tool for conservation? Trends in Ecology \& Evolution, 26(9), 441-447.

Butterworth, D. S., \& Punt, A. E. (1999). Experiences in the evaluation and implementation of management procedures. ICES Journal of Marine Science, 56(6), 985-998.

Cooke, J. G. (1999). Improvement of fishery-management advice through simulation testing of harvest algorithms. ICES Journal of Marine Science, 56(6), 797-810.

Dichmont, C. M., Ellis, N., Bustamante, R. H., Deng, R., Tickell, S., Pascual, R., ... \& Griffiths, S. (2013). EDITOR'S CHOICE: Evaluating marine spatial closures with conflicting fisheries and conservation objectives. Journal of Applied Ecology, 5o(4), 1060-1070.

Ecosystems Approach to Fisheries. (2011). EAF planning and implementation tools. Management Strategy Evaluation (MSE). EAF Tool fact sheets. Retrieved from http://www.fao.org/fishery/eaf-net/eaftool/ eaf_tool_50. Rome. Updated 29 November 2011. 
Fulton, E. A., Punt, A. E., Dichmont, C. M., Harvey, C. J., \& Gorton, R. (2019). Ecosystems say good management pays off. Fish and Fisheries, 2o(1), 66-96.

Fulton, E. A., Smith, A. D., Smith, D. C., \& Johnson, P. (2014). An integrated approach is needed for ecosystem based fisheries management: insights from ecosystem-level management strategy evaluation. PloS one, 9(1), e84242.

Goethel, D. R., Lucey, S. M., Berger, A. M., Gaichas, S. K., Karp, M. A., Lynch, P. D., \& Walter III, J. F. (2019). Recent advances in management strategy evaluation: introduction to the special issue "Under pressure: addressing fisheries challenges with Management Strategy Evaluation". Canadian Journal of Fisheries and Aquatic Sciences, 76(10), 1689-1696.

Goethel, D. R., Lucey, S. M., Berger, A. M., Gaichas, S. K., Karp, M. A., Lynch, P. D., ... \& Wilberg, M. J. (2018). Closing the feedback loop: on stakeholder participation in management strategy evaluation. Canadian Journal of Fisheries and Aquatic Sciences, (999), 1-19.

Hofmann, E., Bundy, A., Drinkwater, K., Piola, A. R., Avril, B., Robinson, C., ... \& Xu, Y. (2015). IMBER-Research for marine sustainability: Synthesis and the way forward. Anthropocene, 12, 42-53.

Hofmann, E. E. and the IMBeR Scientific Steering Committee (eds.). (2016). IMBeR 2016-2025: Science Plan and Implementation Strategy. IMBeR International Project Office, Bergen, Norway. Retrieved from http://www.imber.info/science/ imber-science-plan-and-implementation-strategy-spis

International Council for the Exploration of the Sea. (2019). Workshop on guidelines for management strategy evaluations (WKGMSE2). ICES Scientific Reports, 1(33), 162 pp. doi:10.17895/ices.pub.5331

Hurtado-Ferro, F., Hiramatsu, K., \& Shirakihara, K.(2010). Allowing for environmental effects in a management strategy evaluation for Japanese sardine. ICES Journal of Marine Science, 67(9), 2012-2017.

Martell, S., Leaman, B. M., \& Stewart, I. J. (2013). Developments in the Management Strategy Evaluation process, fisheries objectives, and implications for harvest policy and decision making. In International Pacific Halibut Commission Ninetieth Annual Meeting.

Miller, T. J., Blair, J. A., Ihde, T. F., Jones, R. M., Secor, D. H., \& Wilberg, M. J. (2010). FishSmart: an innovative role for science in stakeholder-centered approaches to fisheries management. Fisheries, 35(9), 424-433.

Miller, T. J., Hare, J. A., \& Alade, L. A. (2016). A state-space approach to incorporating environmental effects on recruitment in an age-structured assessment model with an application to Southern New England yellowtail flounder. Canadian Journal of Fisheries and Aquatic Sciences, 73(8), 1261-1270.

Pershing, A. J., Alexander, M. A., Hernandez, C. M., Kerr, L. A., Le Bris, A., Mills, K. E., ... \& Sherwood, G. D. (2015). Slow adaptation in the face of rapid warming leads to collapse of the Gulf of Maine cod fishery. Science, 350(6262), 809-812.

Punt, A. E. (2011). The impact of climate change on the performance of rebuilding strategies for overfished groundfish species of the U.S. west coast. Fisheries Research, 109(2-3), 320-329.

Punt, A. E., Butterworth, D. S., de Moor, C. L., De Oliveira, J. A., \& Haddon, M. (2016). Management strategy evaluation: Best practices. Fish and Fisheries, 17(2), 303-334.

Punt, A. E., Smith, A. D., \& Cui, G. (2001). Review of progress in the introduction of management strategy evaluation (MSE) approaches in Australia's South East Fishery. Marine and Freshwater Research, 52(4), 719-726.

Rochet, M. J., \& Rice, J. C. (2009). Simulation-based management strategy evaluation: ignorance disguised as mathematics?. ICES Journal of Marine Science, 66(4), $754-762$.

Sainsbury, K. J., Punt, A. E., \& Smith, A. D. (2000). Design of operational management strategies for achieving fishery ecosystem objectives. ICES Journal of Marine Science, 57(3), 731-741.

Szuwalski, C. S., \& Punt, A. E. (2012). Fisheries management for regime-based ecosystems: a management strategy evaluation for the snow crab fishery in the eastern Bering Sea. ICES Journal of Marine Science, 70(5), 955-967.

Tommasi, D., Stock, C. A., Hobday, A. J., Methot, R., Kaplan, I. C., Eveson, J. P., ... \& Pershing, A. (2017). Managing living marine resources in a dynamic environment: the role of seasonal to decadal climate forecasts. Progress in Oceanography, 152, 15-49. 